\title{
Fontes de risco e medidas de gestão em vinícolas do Rio Grande do Sul: um estudo a partir da percepção dos enólogos
}

\begin{abstract}
Resumo
Este artigo analisa a percepção dos enólogos acerca das fontes de risco no negócio do vinho e as medidas de gestão eleitas no intuito de controlá-las. O estudo caracteriza-se como uma pesquisa exploratória, que, apesar de se utilizar de algumas ferramentas estatísticas de análise, adota uma amostragem não probabilística e intencional. $\mathrm{O}$ instrumento de coleta de dados foi aplicado a dezesseis enólogos de vinícolas distintas, localizadas majoritariamente na Serra Gaúcha, no Rio Grande do Sul (RS). As principais considerações dizem respeito à grande relevância que os entrevistados atribuem ao risco mercadológico, elegendo-o como a principal fonte de risco para o negócio do vinho. $\mathrm{O}$ estudo também aponta para a vantagem de se empregar a técnica de escalonamentos multidimensionais para compreender as relações existentes entre as diversas fontes de risco, a partir da percepção dos enólogos.
\end{abstract}

\author{
Cláudio Vinicius Silva Farias" \\ Caroline da Costa Duschitz" \\ Leonardo Xavier da Silva**
}

Palavras-chave: Vitivinicultura. Risco. Escalonamentos multidimensionais.

* Professor Assistente do Instituto Federal de Educação, Ciência e Tecnologia do Rio Grande do Sul, Campus Porto Alegre. Doutorando em Desenvolvimento Rural no Programa de Pós-Graduação em Desenvolvimento Rural da Universidade Federal do Rio Grande do Sul. Mestre em Economia pela Universidade do Rio dos Sinos. Graduado em Administração de Empresas pela Universidade Federal do Rio Grande do Sul. Pós-graduado em Gestão Ambiental. E-mail: claudio.farias@poa.ifrs.edu.br

** Professora Assistente de Administração na Universidade Estadual do Rio Grande do Sul. Mestre em Administração de Empresas e bacharel em Administração pela Universidade Federal do Rio Grande do Sul. Bacharel em Relações Públicas pela Pontifícia Universidade Católica do Rio Grande do Sul. E-mail: caroline-duschitz@uergs.edu.br

*** Professor Adjunto do Departamento de Economia e Relações Internacionais (DERI) da Universidade Federal do Rio Grande do Sul (UFRGS), estando vinculado aos programas de pós-graduação em Desenvolvimento Rural (PGDR) e em Agronegócios (PPGAgronegócios). Doutor em Economia pela UFRGS. Mestre em Economia Rural pela UFRGS. Bacharel em Ciências Econômica pela Pontifícia Universidade Católica do Rio Grande do Sul. E-mail: leonardo.xavier@ufrgs.br

http://dx.doi.org/10.5335/rtee.v21i45.6191

Submissão: 15/04/2015. Aceite: 25/10/2015. 


\section{Introdução}

$\mathrm{Na}$ atualidade, cada vez mais questões gerenciais são pautadas sobre as discussões sobre o desempenho de unidades agroindustriais. Particularmente, aspectos relacionados à gestão de risco desses empreendimentos ocupam uma posição de destaque nos últimos anos (BORGES; MACHADO, 2012; AKCAOZ et al., 2009; NELSON, 1997). Igualmente, estudos empíricos e teóricos demonstram a importância de se considerar a percepção dos agentes econômicos, sobretudo daqueles responsáveis pela tomada de decisão, com relação aos fatores de risco inerentes ao negócio (NELSON, 1997; FLATEN et al., 2005; VALE et al., 2007).

Ao considerar os fatores de risco que os gestores percebem como importantes em um dado negócio, pode-se avaliar como são desenvolvidos os mecanismos para gerenciar tais situações. Para os produtores rurais, a gestão desses fatores torna-se uma tarefa mais laboriosa, uma vez que, por definição, os empreendimentos agroindustriais estão mais sujeitos aos riscos externos (que extrapolam a capacidade de controle dos gestores) do que outros segmentos da economia, como a indústria e os serviços. Sobretudo, tais riscos externos estão ligados a fatores climatológicos (chuvas, secas, vendavais, etc.) e biológicos (disseminação de pragas, particularidades ecológicas, etc.).

O setor vitivinícola brasileiro, para além dos fatores climatológicos e biológicos que conformam consideravelmente essa indústria, está sujeito a outras modalidades de riscos, tais como a exposição aos produtores importados, a ampliação da regulamentação fitossanitária e a ausência de mão de obra qualificada em maior número. Somam-se a esses fatores os problemas relacionados a um histórico de baixa qualidade dos produtos nacionais e o desconhecimento (e falta de hábito) dos consumidores no que tange à apreciação de vinhos e espumantes (FARIAS, 2008; VARGAS, 2002; MELLO, 2007).

O presente artigo pretende analisar como os enólogos, responsáveis pela produção e qualidade dos vinhos nas vinícolas, percebem as fontes de risco para o negócio do vinho, e que medidas eles elegem como principais para tentar controlar esses fatores.

Este estudo caracteriza-se como uma pesquisa exploratória, que, apesar de se utilizar de algumas ferramentas estatísticas de análise, adota uma amostragem não probabilística e intencional. O instrumento de coleta de dados foi aplicado a dezesseis enólogos de vinícolas distintas, todas localizadas na Serra Gaúcha. O artigo está organizado em cinco seções, além da introdução: a) breve revisão da literatura sobre a percepção e a gestão do risco; b) caracterização do setor vitivinícola da 
Serra Gaúcha; c) justificativa do método utilizado; d) descrição acerca dos respondentes e apresentação dos principais resultados obtidos; e) considerações finais.

\section{Fatores de risco na atividade agroindustrial}

Risco pode ser compreendido como a possibilidade de perda que um negócio pode vir a ter em decorrência de eventos desfavoráveis. Ainda que se considere que tal perda possa gerar efeitos negativos sobre a viabilidade do negócio, deve-se considerar que a empresa que assume maiores níveis de risco está buscando maiores níveis de retorno. Dessa forma, deve-se considerar que risco e retorno são variáveis interdependentes, logo, a eliminação completa do risco geraria um ambiente de estagnação nos negócios da empresa, ao menos no que tange às expectativas de retorno.

Kimura afirma que o mais importante para o gestor de um dado negócio é identificar as classes e a intensidade dos riscos que a organização está disposta a assumir e, a partir daí, buscar estabelecer formas de maximizar o seu retorno. Segundo o autor, "[...] a atividade agropecuária ou agroindustrial está sujeita a diversos fatores de risco que podem influenciar o resultado do negócio" (1998, p. 53).

Uma das muitas características específicas das organizações agroindustriais é a concentração de suas operações em poucas variedades de commodities, deixando-as sujeitas às frequentes oscilações de produção, qualidade e preço, ou seja, a produção rural sofre influências de fatores, cuja previsão e controle são imponderáveis, especialmente no que tange às condições do clima e ao ataque de pragas (BIGNOTTO; BAROSSI; SAMPAIO, 2004).

De acordo Borges e Machado (2012), no contexto do agronegócio os riscos são fatores inerentes. As incertezas (consideradas fontes primárias dos riscos) estão relacionadas à instabilidade climática, ao surgimento e à rápida disseminação de pragas e doenças, a oscilações na demanda, à variabilidade de preços e da produção. De acordo com Börner (2006), diversas são as origens para esses riscos, tais como: o risco da produção (clima e pragas), o risco de mercado (flutuações no preço e demanda), o risco institucional (governamental e legal), o risco humano (acidentes, doenças, falta de mão de obra). Ainda, todos esses fatores contribuem para que as rendas apresentem algum grau de variabilidade ao longo do tempo. Por conta disso, "[...] estudos que buscam a eficiência na exploração agrícola não devem considerar apenas a alocação ótima dos recursos disponíveis. O fator risco deve ser considerado" (KIMURA, 1998, p. 52). 
Segundo Kimura (1998, p. 53-54), os fatores de risco podem ser classificados em diferentes classes, quais sejam:

a) risco de produção: está ligado a um processo biológico, logo, está sujeito às condições climáticas, às propriedades do solo, ao ataque de pragas e doenças, configurando-se em uma ampla gama de possibilidades para a estimativa da quantidade final produzida bem como para a qualidade esperada dos produtos. O surgimento de novas tecnologias pode não eliminar a presença do risco de produção, podendo, inclusive, ampliá-lo. De acordo com Bignotto, Barossi e Sampaio, o risco de produção é um dos principais responsáveis pelas variações das safras, "devido à dificuldade em prever, na época do plantio, o que irá ocorrer durante o processo até a colheita" (2004, p. 26);

b) riscos operacionais: caracterizados pelas falhas na operacionalização dos processos de produção. Um exemplo pode ser as falhas no plantio, na adubação, na irrigação ou até mesmo na determinação do momento adequado da colheita. Segundo Bignotto, Barossi e Sampaio (2004), esses riscos são administráveis com o treinamento dos funcionários do estabelecimento $\mathrm{e}$ com a divulgação de procedimentos operacionais e de controles adequados;

c) riscos financeiros: ocorrem quando a condução da política econômica, resultante das configurações macroeconômicas, pode produzir perdas nas organizações agroindustriais em virtude do aumento da carga tributária ou dos encargos provenientes dos seus passivos onerosos (efeito da ampliação das taxas de juros sobre as dívidas, por exemplo);

d) riscos de mercado: são elementos importantes na gestão das atividades agroindustriais, uma vez que as flutuações de preços dos produtos podem inviabilizar a atividade, ou seja, receitas menores em função de queda de preços produzem resultados insatisfatórios, mesmo quando há um processo produtivo eficiente. Os aspectos relacionados ao excesso de oferta ou falta de demanda de determinado produto, constituem-se como fatores principais dos riscos de mercado.

Nelson (1997) apresenta os principais riscos que devem ser acompanhados de perto pelo trabalho dos gerentes, quais sejam: risco de produção; risco de mercado, risco financeiro, risco de obsolescência, risco de perda casual, risco legal e risco humano. Segundo o autor, identificar os riscos de um negócio é o passo inicial para se tomar decisões, especialmente em ambientes de complexidade.

Com relação à implementação de uma política de gestão de riscos para organizações do sistema agroindustrial, deve-se, inicialmente, identificar o nível de 
exposição aos riscos que ela pode assumir. O nível de exposição aos riscos depende do perfil daqueles que tomam as decisões em relação ao risco e ao grau de sustentabilidade das perdas que possam vir a ocorrer. Existem, basicamente, três tipos de perfis perante os riscos: a) os indivíduos avessos ao risco; b) os indivíduos que são neutros ao risco; e c) os indivíduos propensos ao risco.

De modo geral, o indivíduo avesso ao risco é caracterizado como "aquele que não se sente confortável em assumir riscos, exigindo, portanto, retornos maiores na medida em que é exposto a maiores riscos" (KIMURA, 1998, p. 55). O indivíduo neutro ao risco é indiferente ao retorno exigido em relação ao risco assumido. Por sua vez, o indivíduo propenso ao risco até troca taxas de retorno pela simples possibilidade de assumir um maior nível de risco (KIMURA, 1998). A partir da determinação do perfil de risco daqueles que decidem na organização, deve-se estabelecer o grau de sustentabilidade de perdas, ou seja, o limite da sua capacidade econômico-financeira para suportar perdas no caso de eventos desfavoráveis.

\section{Produção vinícola no Rio Grande do Sul}

A indústria brasileira de vinhos é concentrada tanto em termos de quantidade e localização das principais empresas produtoras quanto em relação ao consumo. Cerca de $90 \%$ da produção nacional de vinhos está concentrada no estado do Rio Grande do Sul, notadamente na Serra Gaúcha (VARGAS, 2002; BRASIL, 2008). O consumo também é concentrado nessa região.

O setor industrial vinícola do RS é formado por 738 empresas (BRASIL, 2008). Dessas, 88\% estão localizadas em nove municípios (Bento Gonçalves, Flores da Cunha, Farroupilha, Caxias do Sul, Garibaldi, Monte Belo do Sul, Nova Pádua, São Marcos e Antônio Prado), com cerca de sessenta empresas localizadas em outras regiões do estado (FARIAS, 2010).

O número de estabelecimentos vinícolas no RS ampliou-se, de 2001 a 2009, cerca de 60\% em termos de empresas registradas no Instituto Brasileiro do Vinho. Esse crescimento explica-se não somente pelo aumento da comercialização de vinhos e sucos de uva, como também por uma ampliação do chamado negócio do vinho. Inúmeras empresas (vitícolas e vinícolas) estão investindo nos últimos anos no incremento de seus negócios originais, indo para além da produção de uvas e vinhos, agregando valor às suas marcas com uma série de serviços acessórios, todos ligados ao vinho, tais como restaurantes, pousadas, hotéis, etc.

O mercado de vinhos compreende, basicamente, os vinhos de consumo corrente ou vinhos comuns, produzidos a partir de uvas de variedades americanas 
e híbridas, e vinhos finos, que são elaborados a partir de uvas de castas nobres, da espécie Vitis vinífera. Nos últimos quinze anos, houve um intenso movimento de valorização da produção, com investimentos em uvas varietais. No entanto, a produção de vinhos comuns ainda é a tônica do setor, respondendo por $60 \%$ da produção total de vinhos e derivados em 2009 (BRASIL, 2008; FARIAS, 2010).

A vitivinicultura da Serra Gaúcha caracteriza-se pelo predomínio (ou foco) nos mercados locais e nacionais, a despeito do substancial esforço de um grupo de empresas na direção da internacionalização como uma de suas metas principais (VARGAS, 2002). Tais estratégias de internacionalização têm também como finalidade a ampliação do reconhecimento do mercado interno. A busca pela valorização das marcas no mercado nacional passa também pela participação em feiras e premiações internacionais, cujo objetivo principal é a agregação de valor aos produtos via distinção das marcas (FARIAS; CAMPREGHER, 2008).

Vargas (2002) categoriza as empresas presentes no arranjo vitivinícola da Serra Gaúcha em três segmentos distintos, a saber:

a) empresas com capacidade de produção acima de 6 milhões de litros/ano, que atuam principalmente na produção de vinhos finos e espumantes. Encontram-se nesse segmento tanto grandes empresas de capital nacional quanto divisões de grupos estrangeiros com filiais na região;

b) pequenas vinícolas e cooperativas que produzem menos de 3 milhões de litros/ano, porém são responsáveis por mais de $50 \%$ da produção de vinhos do arranjo. Grande parte dessas empresas dedica-se à produção de vinhos comuns e apenas nos últimos anos iniciou a produção (ainda pequena) de vinhos finos;

c) pequenas cantinas familiares, que se especializaram na produção de vinhos finos, conquistando parcelas significativas de nichos do mercado nacional, anteriormente atendidas pelas empresas do primeiro segmento (nacionais ou estrangeiras).

$\mathrm{O}$ que se percebe, em especial nas pequenas cantinas de produção familiar, é que o número de funcionários (formais e informais) varia conforme o produto principal da empresa. Se a firma foca sua produção na elaboração de vinhos comuns, a quantidade de mão de obra empregada é menor do que naquelas firmas que concentram sua produção nos vinhos finos e em espumantes. $O$ processo de vinificação de produtos finos é mais extenso do que o processamento de vinhos comuns, uma vez que esse, em geral, é vendido a granel, reduzindo boa parte do processo.

Por diversas razões, um número cada vez maior de vinícolas orienta sua produção para a elaboração de vinhos finos e espumantes. Esse movimento de orientação 
das empresas, em maior ou menor escala, em ofertar em seus portfólios de produtos vinhos finos, exige das empresas esforços adicionais. A produção de vinhos finos demanda um elevado nível de capacitação e investimento de parte das vinícolas, que se reflete, não apenas no nível tecnológico de máquinas e equipamentos utilizados na produção, mas, sobretudo, em um estoque de conhecimentos técnicos e de melhores práticas enológicas (VARGAS, 2002).

A participação dos produtos estrangeiros no mercado nacional de vinhos (fruto de acordos comerciais e de variações da taxa de câmbio) aliada aos excedentes crescentes de vinhos e dos problemas climáticos que têm afetado a produção de uvas em quantidade e qualidade colocam o setor de vinhos finos brasileiros em condições desfavoráveis. Em que pese esse cenário, o setor está investindo no aumento da qualidade dos vinhos e na promoção de indicações geográficas, buscando a valorização do produto pelos valores territoriais e culturais. Tais esforços têm recebido o apoio institucional de diversas organizações vinculadas à uva e ao vinho, com o objetivo principal de aumentar a competitividade das empresas do setor.

\section{Aspectos metodológicos}

O método empregado para a consecução dos objetivos deste artigo deu-se por meio da aplicação de questionários estruturados, com um enfoque descritivo e considerando uma amostragem não probabilística. A aplicação dos questionários foi precedida por um conjunto de entrevistas em profundidade, que foram realizadas com especialistas do setor e com representantes de instituições de ensino e pesquisa e órgãos de representação e apoio. Informações obtidas em resultados de pesquisas anteriores também foram incorporadas no momento da elaboração do instrumento de coleta de dados (FARIAS, 2010; FARIAS; CAMPREGHER, 2008).

O questionário foi aplicado em dezesseis vinícolas, todas inseridas no arranjo vitivinícola da Serra Gaúcha. ${ }^{1}$ Optou-se pela aplicação presencial de todos os questionários. Tal estratégia foi adotada a fim de garantir a completa compreensão das questões por parte dos respondentes.

Os agentes que participaram desta pesquisa foram os enólogos, responsáveis pelo processo produtivo nas vinícolas. Em muitos casos, o papel do enólogo extravasa as funções da produção, adentrando em outros aspectos gerenciais do negócio, com interfaces mercadológicas e na gestão da mão de obra.

Esta pesquisa buscou identificar a percepção desses profissionais, que, de forma significativa, norteiam os rumos das vinícolas em que trabalham e interferem diretamente nos horizontes do setor vitivinícola como um todo. Entender 
a percepção desses profissionais sobre os fatores de risco que envolvem esses negócios pode ajudar a compreender as transformações pelas quais esse setor passa.

\subsection{Escalonamento multidimensional}

Para se comparar as proximidades/relacionamentos das diferentes percepções de riscos que envolvem a vitivinicultura do RS (sob a ótica dos enólogos entrevistados), solicitou-se aos respondentes que manifestassem suas opiniões em relação ao momento atual e em relação ao período de cinco anos atrás. Para tanto, optou-se por utilizar uma técnica exploratória multivariada de análise de dados. Nesse caso, utilizou-se o escalonamento multidimensional (EMD), ${ }^{2}$ também conhecido como mapeamento perceptual ou mapa de percepção.

$\mathrm{O}$ escalonamento multidimensional permite representar, em um sistema dimensional reduzido, as proximidades (semelhanças/dessemelhanças) entre sujeitos ou objetos/variáveis, a partir de um conjunto de atributos multivariados medidos ou percebidos (MARÔCO, 2011). Essa técnica de análise explicita a estrutura dos dados de julgamento de maneira gráfica espacial, permitindo a identificação de dimensões latentes na percepção sobre proximidades entre atributos e o seu posicionamento em um mapa perceptual.

No EMD, as semelhanças e dessemelhanças entre as variáveis refletem-se como distâncias entre pontos, de modo que variáveis semelhantes são agrupadas, enquanto que as diferentes encontram-se distantes no espaço multidimensional. $\mathrm{O}$ output do EMD assume a forma de um conjunto de gráficos de dispersão (mapas de percepção), em que os eixos são as dimensões subjacentes e os pontos são os produtos, os candidatos, opiniões ou outros objetos de comparação (GARSON, 2012).

Para medir a distância entre os pontos, tendo-se em vista a escala quantitativa utilizada, optou-se pela distância euclidiana, que é a mais frequente em aplicações de EMD (MARÔCO, 2011). A distância euclidiana é baseada em uma medida entre os objetos dentro de um sistema de coordenadas cartesianas (gráfico bidimensional).

Ainda, no EMD, há dois tipos de algoritmos utilizados para a obtenção do mapa perceptual/quantificação dos julgamentos de similaridade: Alscal (alternating least squares scaling) e Proxscal (proximity scaling). Neste estudo, optou-se por manter a análise multidimensional a partir do Alscal, que ressalta a importância e agrupa mais as dessemelhanças (MARÔCO, 2011). O algoritmo Alscal é mais eficiente com medidas de dessemelhanças/distâncias do que com medidas de semelhanças/proximidades (GARSON, 2012). 
Para a interpretação do Alscal, verificam-se alguns critérios de avaliação:

a) Stress, que avalia a medida de ajuste dos modelos EMD, em que quanto menor o stress, melhor o ajuste. Stress mede a diferença entre as distâncias entre os pontos no espaço computadorizado no EMD e as distâncias correspondentes reais (GARSON, 2012). De acordo com Marôco (2011), a qualidade da solicitação de EMD pode ser classificada da seguinte forma:

Quadro 1 - Classificação do EMD quanto ao nível de stress

\begin{tabular}{|c|c|}
\hline STRESS-I & Qualidade da solução de EMD \\
\hline$\geq 0,2$ & Pobre \\
{$[0,1 ; 0,2[$} & Razoável \\
{$[0,05 ; 0,1[$} & Boa \\
{$[0,025 ; 0,05[$} & Excelente \\
0 & Perfeita \\
\hline
\end{tabular}

Fonte: Marôco (2011, p. 579).

b) $\mathrm{R}^{2}$ ou RSQ, que é a correlação ao quadrado das distâncias de entrada com as distâncias escaladas nas dimensões computacionais usando as coordenadas do EMD, isto é, reflete a proporção da variância dos dados de distância entrados explicados pelos dados da escala do modelo (GARSON, 2012). Quanto maior o valor, maior proporção da variância das disparidades é explicada pelo EMD, maior o ajuste; medidas de 0,60 ou melhores são consideradas aceitáveis (HAIR JR. et al., 2005).

Ainda que se tenha utilizado certas ferramentas de análise estatística, é importante ressaltar que o presente estudo caracteriza-se como sendo de natureza exploratória. A partir da validação do instrumento de coleta de dados utilizado, pretende-se ampliar a pesquisa, aumentando a amostra analisada, o que possibilitará realizar análises mais apuradas e estabelecer afirmações mais conclusivas com relação ao tema. A seguir, serão apresentadas as principais análises possíveis com a amostra disponível.

\section{Análise}

\subsection{Perfil da amostra}

Para descrever o perfil da amostra, foram questionadas variáveis relativas às características da vinícola e também ao perfil profissional do respondente: capacidade anual de produção de vinhos finos, percentual de vinhos finos produzidos, 
tipos de produtos produzidos, se a vinícola produz sua própria uva, se arrenda terras para terceiros, o tamanho da plantação de uvas viníferas, rendimento médio das plantações de uvas viníferas, financiamento do plantio, formas de comercialização dos vinhos, idade média dos equipamentos utilizados para a vinificação, se a empresa recebe assistência produtiva, tempo em que o profissional exerce a profissão de enólogo e tempo em que o profissional trabalha na vinícola sobre a qual respondeu o questionário.

Entre as empresas deste estudo, oito vinícolas têm capacidade anual de produção de vinho de até 50 mil litros, cinco vinícolas, de até 500 mil litros, e duas vinícolas têm capacidade de produção maior do que 1 milhão de litros/ano, sendo que, em média, $62,7 \%$ da produção correspondem a vinhos finos. Além dos vinhos finos, cinco empresas indicaram que também produzem vinhos comuns, sete indicaram que também produzem suco de uva e onze indicaram que também produzem espumantes.

A área média de uvas plantadas é de cerca de 20 hectares, com um rendimento (médio) na colheita de uvas viníferas de cerca de 6 toneladas/hectare. O respondente com menos experiência como enólogo afirmou exercer a profissão há um ano, enquanto que o mais experiente relatou estar nesse mercado há 25 anos.

Quando perguntados sobre o financiamento do plantio, onze enólogos afirmaram que a vinícola utilizava-se de capital próprio, enquanto quatro apontaram o uso exclusivo de capital oriundo de instituições financeiras. A idade média das instalações e dos equipamentos empregados na vinificação é de nove anos. Essa informação confirma estudos recentes que apontam para a atualização tecnológica das vinícolas, sobretudo quando se trata de tecnologia do processo produtivo na transformação de uvas em vinho - em especial em vinícolas com maior operação em vinhos finos (FARIAS, 2010).

Com relação às vendas, sete vinícolas têm como principal canal de vendas bares, restaurantes e hotéis, quatro vinícolas apontaram atacadistas e varejistas como seu melhor veículo de comercialização, e em cinco empresas o principal canal de vendas é a relação direta com os consumidores.

Perguntados se recebiam alguma forma de assistência técnica produtiva, os enólogos de onze vinícolas responderam afirmativamente, mencionando, em cinco casos, que os fornecedores de insumos enológicos são os agentes de extensão rural, ficando a Embrapa em segundo lugar (três casos). Sobre a percepção dos enólogos quanto à demanda de vinhos finos no Brasil, nos últimos cinco anos, onze enólogos afirmaram que a demanda aumentou, e apenas um dos respondentes indicou uma redução na demanda de vinhos, especialmente vinhos finos. 
Por fim, na etapa descritiva da amostra, foi solicitado que os profissionais informassem qual o fator de risco que mais impactaria o negócio do vinho. $\mathrm{Na}$ percepção dos enólogos, a resposta mais acentuada foi o risco mercadológico (nove casos), seguido do risco climatológico (quatro casos). Tal situação, até certo ponto, revela uma singularidade do segmento vinícola do $\mathrm{RS}$, que aponta para as questões de mercado e preço como os principais fatores que podem fragilizar a gestão das empresas do setor. A literatura, em geral, aponta que unidades produtivas rurais tendem a preocupar-se mais com as questões climatológicas e biológicas, ficando outros fatores em segundo plano (NELSON, 1997; KIMURA, 1998). Em caso de ampliação da pesquisa, será possível avaliar se esse é um comportamento das vinícolas gaúchas ou apenas o reflexo de posições pessoais dos enólogos entrevistados.

\subsection{Percepções de riscos e medidas de gestão}

Aos pesquisadores coube também analisar se as percepções sobre o risco sofreram alterações nos últimos anos. Para tanto, após o cruzamento dos dados, percebeu-se que, avaliando as percepções de risco de hoje e de cinco anos atrás, existe pouca diferença entre as opiniões dos enólogos, como se pode verificar no Gráfico 1.

Gráfico 1 - Percepção da relevância das fontes de risco hoje vs. cinco anos atrás

\section{Percepção da Relevância das Fontes de Risco}

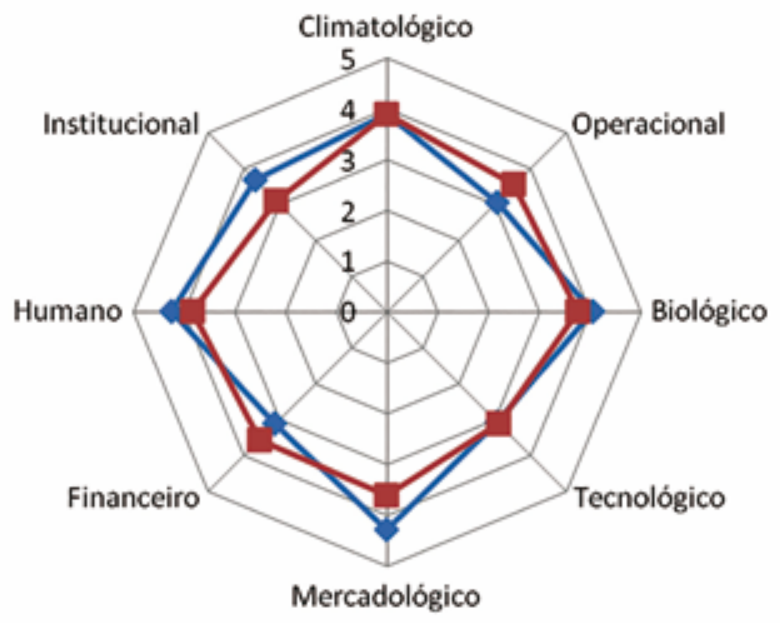

—Percepção de Risco Hoje

-5 anos atrás

Fonte: elaboração dos autores com base em dados da pesquisa. 
Apenas os fatores mercadológico e institucional apresentavam uma leve retração, em relação às percepções no presente. Os demais apresentam situações de muita semelhança. Particular atenção pode ser dada ao fator tecnológico, que apresenta uma percepção quanto ao risco muito próxima nos dois períodos, reforçando a ideia de que os aspectos tecnológicos do setor já se encontram estabilizados, ao menos entre as empresas da Serra Gaúcha.

Aplicando aos dados a análise de escalonamento multidimensional, pode-se avaliar a manifestação de interessantes modelos de explicação às percepções de risco dos enólogos. Primeiramente, há que se considerar que o modelo apresenta um baixo nível de stress $(0,11)$ e um elevado RSQ $(0,90)$, indicando um elevado grau de consistência das informações, a partir dos dados gerados. Fatores mercadológicos, tais como aumento dos preços dos insumos, da oferta de vinhos importados e de dificuldades logísticas, apareceram com forte grau de proximidade com os fatores biológicos (ataque por pragas e doenças) como também com os fatores institucionais (aumento no rigor das leis fitossanitárias e alterações no quadro político-econômico).

A explicação parece lógica: um ataque por pragas ou doenças, que afete as videiras, provavelmente acarretará na necessidade de aplicação de maiores quantidades de defensivos agrícolas, o que provocará um aumento nos preços, gerando aumento nos custos de produção do vinho. Tal situação de risco amplia-se ao se compreender que muitas dessas doenças e pragas não se restringem apenas a uma propriedade e que podem se alastrar facilmente por toda uma região produtiva. Imagine-se, com isso, os transtornos sobre os sistemas logísticos e os eventuais impactos sobre os preços dos produtos finais.

Pragas, doenças e problemas logísticos, quando manifestos em um mesmo momento, podem causar forte impacto sobre a capacidade competitiva das vinícolas afetadas. Nesse quadro de incerteza e risco, a entrada de novos produtos, oriundos de países tradicionalmente produtores de vinhos finos, assevera ainda mais o cenário desenhado. Ainda, pode-se considerar que o aumento no rigor das leis fitossanitárias e a devida adequação dos processos produtivos a essas novas exigências podem igualmente afetar as vinícolas, seja pelo aumento dos custos, seja por uma eventual retirada de produtos de circulação (em função de fiscalizações realizadas). Por isso, parece ser consistente a percepção dos enólogos com relação à proximidade entre os riscos mercadológico, biológico e institucional, que podem ser visualizados no Gráfico 2. 


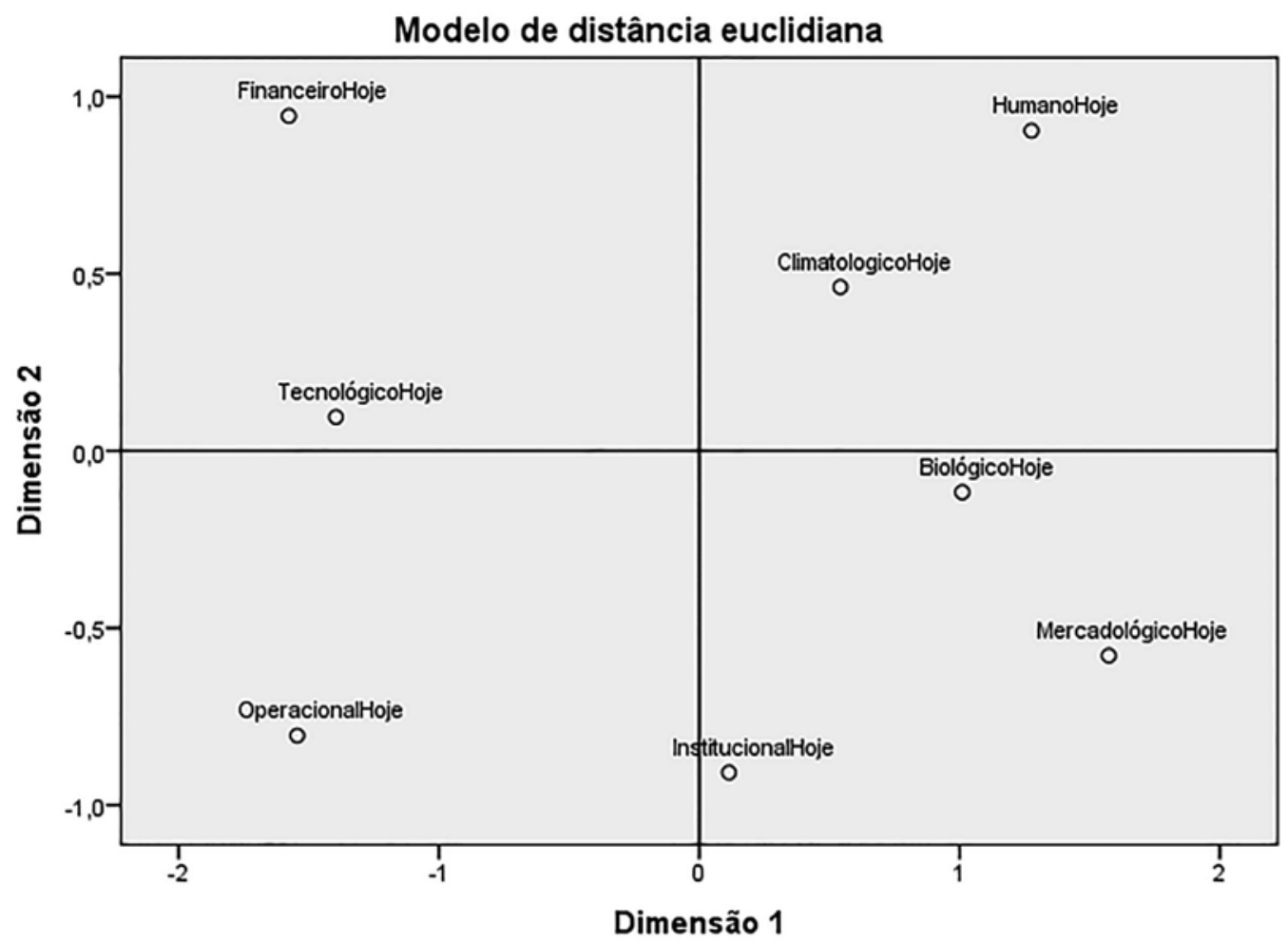

Fonte: elaboração dos autores com base em dados da pesquisa.

Medidas MDS: Stress $=0,11761 ; \mathrm{RSQ}=0,90806$.

Existe, também, certa proximidade entre as percepções de risco climatológico e humano. Os riscos climatológicos estão ligados à falta/excesso de chuva ou à ocorrência de granizo nas unidades produtoras. Esse é o risco por excelência dos empreendimentos agrícolas. Por vezes, e tradicionalmente, a manifestação de tais riscos provoca a necessidade de usos intensivos de mão de obra, em esforços conjuntos entre produtores, em mutirões de ajuda mútua, unindo produtores e seus empregados. No entanto, ao longo dos anos, a mão de obra rural tem se reduzido não apenas em termos quantitativos, mas também em termos qualitativos, afetando a produção de uvas, que exige certo grau de especialização da produção (que exige mais da força de trabalho). Tal fato acentua-se quando se percebe a incidência de problemas de sucessão familiar nas vinícolas, problema que está afetando sobremaneira o ambiente rural. 
Os fatores tecnológicos e financeiros parecem se aproximar em virtude da relação existente entre as necessidades de investimento, as adequações das videiras e a modernização de máquinas e equipamentos das vinícolas. A redução do crédito é um dos pontos mais salientados pelos enólogos, o que confirma a presença do risco financeiro como um dos principais fatores considerados por tais profissionais.

O único fator que se apresenta isolado dos demais é o risco operacional, que se relaciona a problemas de erro no plantio e na aplicação de defensivos agrícolas bem como a atrasos ocasionados nas colheitas de uvas. De certa forma, tal situação demonstra que as questões operacionais da produção de vinho estão "maduras", sendo os riscos operacionais da produção de uvas facilmente identificados pelos enólogos.

Após a avaliação das percepções de riscos, foi solicitado aos enólogos que apontassem quais eram as principais medidas de gestão dos riscos efetivamente utilizadas em suas vinícolas. As medidas de combate aos riscos mais citadas foram: acompanhamento de previsões do tempo e controle/redução dos custos de produção. As medidas menos citadas foram: busca de informações sobre tendências futuras e ações e planos governamentais. As indicações das medidas adotadas podem ser visualizadas no Quadro 2.

Quadro 2 - Medidas de gestão de risco: utilização e relevância

\begin{tabular}{|c|c|c|c|c|c|c|}
\hline & \multirow{3}{*}{ Medidas de Gestão de Risco } & \multirow{2}{*}{\multicolumn{2}{|c|}{$\begin{array}{l}\text { Utilização Efe tiva da Medida } \\
\text { Respostas Múltipla Escolha }\end{array}$}} & \multicolumn{3}{|c|}{ Relevância da Medida } \\
\hline & & & & \multicolumn{3}{|c|}{ Resposta Única } \\
\hline & & $\mathbf{N}$ & Porcentagem & $\mathbf{N}$ & Média & Desvio padrão \\
\hline \multirow{2}{*}{ Climatológico } & Acompanhamento de previsões do tempo & 12 & $8,6 \%$ & 16 & 4,00 & 1,095 \\
\hline & Seguros contra intempéries & 6 & $4,3 \%$ & 16 & 3,75 & 1,000 \\
\hline \multirow{2}{*}{ Operacional } & Treinamento e qualificação dos trabalhadores & 9 & $6,4 \%$ & 16 & 3,69 & 1,493 \\
\hline & Aumento da capacidade dos maquinários & 8 & $5,7 \%$ & 16 & 3,19 & 1,167 \\
\hline \multirow{3}{*}{ Biológico } & Rotação de culturas & 5 & $3,6 \%$ & 16 & 2,94 & 1,482 \\
\hline & Implantação de variedades resistentes & 6 & $4,3 \%$ & 16 & 3,38 & 1,500 \\
\hline & Monitoramento e manejo integrado de pragas & 6 & $4,3 \%$ & 16 & 3,56 & 1,459 \\
\hline \multirow{3}{*}{ Tecnológico } & Atualização de maquinários & 5 & $3,6 \%$ & 16 & 3,31 & 1,195 \\
\hline & Aquisição de novas mudas varietais & 5 & $3,6 \%$ & 16 & 2,88 & 1,204 \\
\hline & Contratação de consultoria/assistência técnica & 6 & $4,3 \%$ & 16 & 2,56 & 1,459 \\
\hline \multirow{6}{*}{ Mercadológico } & Busca de informações sobre tendências futuras & 2 & $1,4 \%$ & 16 & 3,31 & 1,580 \\
\hline & Diversificação do negócio (turismo, restaurante etc.) & 7 & $5,0 \%$ & 16 & 3,63 & 1,408 \\
\hline & Compra programada de insumos & 8 & $5,7 \%$ & 16 & 3,56 & 1,209 \\
\hline & Variação dos fornecedores e distribuidores & 7 & $5,0 \%$ & 16 & 3,06 & 1,611 \\
\hline & Controle/redução dos custos de produção & 14 & $10,0 \%$ & 16 & 3,81 & 1,559 \\
\hline & Implementação de programas de qualidade & 5 & $3,6 \%$ & 16 & 4,88 & 4,759 \\
\hline \multirow{2}{*}{ Financeiro } & Renegociação de dívidas & 4 & $2,9 \%$ & 16 & 2,81 & 1,377 \\
\hline & Busca de informações contábeis e financeiras & 9 & $6,4 \%$ & 16 & 3,44 & 1,590 \\
\hline \multirow{2}{*}{ Humano } & Plano de qualificação da mão de obra & 5 & $3,6 \%$ & 16 & 3,56 & 1,504 \\
\hline & Implantação de Gestão de RH & 4 & $2,9 \%$ & 16 & 3,31 & 1,493 \\
\hline \multirow{2}{*}{ Institucional } & Informações sobre leis e regulamentos & 5 & $3,6 \%$ & 16 & 3,44 & 1,459 \\
\hline & Informações sobre ações/planos governamentais & 2 & $1,4 \%$ & 16 & 3,38 & 1,628 \\
\hline & Total & 140 & $100,0 \%$ & 16 & 3,43 & 1,56 \\
\hline
\end{tabular}

Fonte: elaboração dos autores com base em dados da pesquisa. 
No mesmo sentido, foi solicitado que os enólogos avaliassem a relevância na adoção de medidas de gestão do risco (independente de sua efetiva utilização nas vinícolas). Mais uma vez, o acompanhamento das previsões do tempo recebeu avaliação elevada, ficando atrás apenas da adoção de programas de qualidade, que foi apontada como a medida de gestão de risco mais relevante. Já a medida menos importante citada foi a contratação de consultoria e assistência técnica. Essa questão relaciona-se ao fato de que um grande número de enólogos apontou que recebe apoio dos seus fornecedores de insumos no que tange à produção e ao manejo de uvas e nos processos de vinificação, o que pode explicar a baixa relevância dessa medida. A renegociação de dívidas também é uma medida pouco relevante, o que pode ser explicado pelo uso majoritário de capital próprio por parte das vinícolas.

Por fim, no Gráfico 3, apresenta-se as médias das informações sobre as percepções de riscos e a relevância das medidas de gestão. Com a análise dos dados, pode-se verificar, para cada fator de risco, a relação entre a percepção e algumas medidas de gestão.

Gráfico 3 - Percepção de risco e relevância das medidas de gestão

\section{Percepção de Risco e Relevância das Medidas de Gestão}

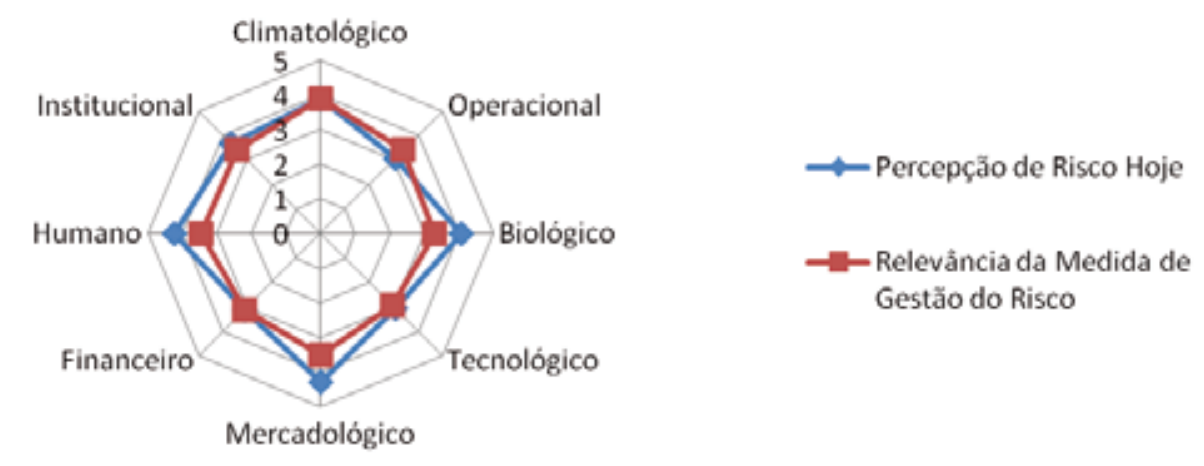

Fonte: elaboração dos autores com base em dados da pesquisa. 
Em três casos, a percepção sobre os riscos foi maior do que a relevância das medidas de gestão. Analisando os fatores humano, mercadológico e biológico, observa-se que as medidas de gestão deveriam estar em destaque, uma vez que são apontados como principais fontes de risco para a vitivinicultura. Os demais fatores de risco parecem ter suas percepções alinhadas com as medidas de gestão.

Como aponta Nelson (1997), a noção de risco deve estar presente no cotidiano da gestão dos empreendimentos rurais, uma vez que tais negócios estão sujeitos a fatores muitas vezes externos ao controle dos gestores/produtores. Por essa razão, deve-se incentivar programas de formação de produtores que incluam o desenvolvimento de metodologias de análise e gestão dos riscos, como forma de melhorar as práticas gerenciais no agronegócio.

\section{Considerações finais}

Este estudo realizou uma análise exploratória para identificar, a partir da revisão da literatura e de entrevistas com especialistas, um modelo capaz de avaliar as fontes de risco e a relevância das medidas de gestão de riscos, aplicadas ao segmento vitivinícola do RS, especialmente das empresas localizadas na Serra Gaúcha. Para tanto, foram entrevistados dezesseis enólogos. Os resultados não são conclusivos, mas apontam algumas indicações importantes, que poderão ser comprovadas a partir da ampliação do escopo da pesquisa.

Destaca-se a importância dada ao fator mercadológico como sendo o principal risco associado ao negócio do vinho, na opinião dos enólogos. Tal situação aponta para uma singularidade, uma vez que a literatura indica que, nos empreendimentos rurais, fatores climatológicos e biológicos aparecem como sendo fontes primordiais de risco. Aparentemente (e para uma conclusão mais efetiva necessita-se de estudos mais aprofundados), os enólogos veem nas situações de mercado e nas variações de preços e custos elementos mais preocupantes do que aspectos relacionados ao ambiente natural.

Por fim, a utilização de escalonamentos multidimensionais mostrou-se uma técnica muito interessante para a avaliação das percepções de risco e pode auxiliar na compreensão das múltiplas dimensões relacionadas ao tema. Necessita-se ampliar a pesquisa para que se possa identificar, de forma mais específica, quais fatores de risco são verdadeiramente relevantes para os enólogos, permitindo a extrapolação das conclusões. 


\title{
Risk sources and Management Measures in Wineries in Rio Grande do Sul: a study from the perception of winemakers
}

\begin{abstract}
The article analyzes the perception of winemakers about the sources of risk in the wine business and management measures they elect to seek to control them. The study is characterized as an exploratory research, which despite using some statistical analysis tools, adopts a non-probabilistic and intentional sampling. The data collection instrument was applied to the sixteen winemakers from different wineries, mostly located in the Serra Gaucha. The main considerations concerning the great importance that respondents attach to the marketing risk, choosing this as the main source of risk for the wine business. The study also points to the advantage of employing the Multidimensional Scaling technique (MDS) to understand the relationship between the various sources of risk, from the perception of winemakers.
\end{abstract}

Keywords: Vitiviniculture. Risk. Multidimentional Scaling.

\section{Fuentes de Riesgos y Medidas de Gestión de bodegas en Rio Grande do Sul: un estudio desde la percepción de enólogos}

\section{Resumen}

El artículo analiza la percepción de los enólogos sobre las fuentes de riesgo en el negocio del vino y las medidas de gestión que eligen para intentar controlarlos. El estudio se caracteriza como una investigación exploratoria, que a pesar de utilizar algunas herramientas de análisis estadístico, adopta una muestra no probabilística e intencional. El instrumento de recolección de datos se aplicó a los dieciséis enólogos de diferentes bodegas, la mayoría localizados en la Sierra Gaucha. Las principales consideraciones sobre la gran importancia que los entrevistados atribuyen al riesgo de comercialización, la elección de este como la principal fuente de riesgo para el negocio del vino. El estudio también señala la ventaja de emplear la técnica de escalamientos multidimensionales (MDS) para entender la relación entre las distintas fuentes de riesgo, a partir de la percepción de los enólogos.

Palabras claves: Vitivinicultura. Riesgo. Escalamientos multidimensionales.

\section{Notas}

1 Um dos respondentes tem sua vinícola localizada em São Joaquim, SC.

2 Do inglês multidimensional scaling (MDS). 


\section{Referências}

AKCAOZ, H. et al. Risk management in dairy farming: a case study in Turkey. Journal of Animal Veterinary Advances, Faisalab/Pakistan, v. 8, p. 949-958, 2009.

BIGNOTTO, E. C; BAROSSI, M.; SAMPAIO, R. Gestão do risco de mercado em organizações do agronegócio. Resenha BM\&F, São Paulo, v. 4, n. 161, p. 26-32, 2004.

BORGES, J. A. R.; MACHADO, J. A. D. Risks and risks management mechanisms: an analysis of the perceptions of producers of agricultural commodities. Interdisciplinary Journal of Research in Business, Lahore/Pakistan, v. 2, n. 5, p. 27-39, 2012.

BÖRNER, J. A bio-economic model of small-scale farmers land use decisions and technology choice in the eastern Brazilian Amazon. 2006. 202 f. Tese (Doutorado em Ciências Agrárias) - Hohen Landwirtschaftlichen Fakultät, Rheinischen-Friedrich-Wilhelms-Universitat zu Bonn, Bonn, Deutschland, 2006. Disponível em: <http://hss.ulb.uni-bonn.de/2006/0747/0747.pdf>. Acesso em: 17 nov. 2006 .

BRASIL. Empresa Brasileira de Pesquisa Agropecuária (Embrapa). Ministério da Agricultura, Pecuária e Abastecimento. Cadastro vitícola do Rio Grande do Sul. Bento Gonçalves: Embrapa Uva e Vinho; Ibravin, 2008. 1 CD.

FARIAS, C. V. S. Aprendizado, inovação e cooperação: um estudo do segmento vinícola do arranjo produtivo da vitivinicultura da Serra Gaúcha. 2010. 193 p. Dissertação (Mestrado em Economia) - Universidade do Vale do Rio dos Sinos, São Leopoldo, 2010.

. Formação da indústria vitivinícola do RS: da imigração italiana aos dias atuais. In: ENCONTRO DE ECONOMIA GAÚCHA, 4, 2008, Porto Alegre. Anais... Porto Alegre: EdiPUCRS; FEE, 2008. 1 CD.

FARIAS, C. V. S.; CAMPREGHER, G. A. Incerteza keynesiana, falhas de coordenação e arranjos institucionais: análise da internacionalização da vitivinicultura brasileira através da Wines from Brazil. In: Fórum de Pesquisa em Internacionalização de Empresas, 1, 4 e 5 de novembro de 2008, São Leopoldo. Anais... São Leopoldo: Oikos, 2008. CD-ROM.

FLATEN, O. et al. Comparing risk perceptions and risk management in organic and conventional dairy farming: empirical results from Norway. Livestock Production Science, Amsterdam/ Netherlands, v. 95, p. 11-25, 2005.

GARSON, G. D. Multidimensional Scaling. Asheboro: Statistical Associates Publishers, 2012.

HAIR JR., Joseph F. et al. Análise multivariada de dados. 5. ed. Porto Alegre: Bookman, 2005.

KIMURA, H. Administração de riscos em empresas agropecuárias e agroindustriais. Caderno de Pesquisas em Administração, São Paulo, v. 1, n. 7, 2 trim. 1998.

KIMURA, H.; PERERA, L. C. J. Modelo de otimização da gestão de risco em empresas não financeiras. Revista Contabilidade \& Finanças da USP, São Paulo, v. 5, n. 37, p. 22-38, jan./abr. 2005.

MARÔCO, João. Análise estatística com o SPSS Statistics. 5. ed. Pero Pinheiro: Report Number, 2011.

MELLO, Loiva M. R. Atuação do Brasil no Mercado Vitivinícola Mundial: panorama 2007. Bento Gonçalves: Embrapa Uva e Vinho, 2007. (Artigos técnicos). Disponível em: <http://www.cnpuv. embrapa.br/publica/artigos/panorama2007_vitivinicola_mundial.pdf>. Acesso em: 23.mar.2015. 
NELSON, A. G. Teaching agricultural producers to consider risk in decision making. In: WESTERN AGRICULTURAL ECONOMICS ASSOCIATION. Annual meeting... Reno, July, p. 13-16, 1997.

VALE, S. M. L. R. et al. Percepção e respostas gerenciais ao risco: um estudo sobre os produtores de leite do programa de desenvolvimento da pecuária leiteira da região de Viçosa - MG. Revista Economia e Agronegócio, Viçosa, n. 5, p. 256-278, 2007.

VARGAS, M. A. Proximidade territorial, aprendizado e inovação: um estudo sobre a dimensão local dos processos de capacitação inovativa em arranjos e sistemas produtivos no Brasil. Tese (Doutorado em Economia) - Instituto de Economia, Universidade Federal do Rio de Janeiro, Rio de Janeiro, 2002. (Documento digital). 